tions in the United States; part two includes a geographical list of personnel and institutions in Canada; and part three provides a similar list for Mexico. Parts four, five and six are delegated to an alphabetical index of colleges and universities in the three countries, and part seven is an alphabetical index of personnel.

\section{Progress in Time Sharing}

IN August 1966, the Computer Board was set up under the chairmanship of Professor B. H. Flowers to carry out, on the basis of planned development, the proposals for providing computers in British universities and research councils in the light of the Flowers Report of January 1966, and for ensuring that the facilities provided were fully used. The five Board members are Professor C. E. H. Bawn of Liverpool University, Professor Gordon Black of the National Computing Centre, Professor D. J. Black of Edinburgh University, $\mathrm{Mr}$ J. K. Steward of ICI, and Lord Halsbury; Mr L. S. Rutterford is secretary to the Board.

In accordance with the recommendations of the Flowers Report, which suggested the expenditure of a total of $£ 17.68$ million over a period of five years for the provision of computer hardware in universities, a regional centre is now being set up in Edinburgh. This is one of the three suggested centres-London, Manchester and Edinburgh-at which large computers with special facilities are to be installed for the general use of universities in the areas. The concept of a multiple access time sharing system at Edinburgh is, however, an additional feature which was not visualized at the time of the report. In comparison with the actual cost of the hardware, additional costs of consoles and software to furnish the multiple access systems are small and will not represent a major item of expenditure above that recommended by the Working Group. The University of Edinburgh will soon be taking delivery of a British computer, the English Electric 4/75. Several agencies have contributed to the cost of the computer and the software: these include the Computer Board, the Ministry of Technology and various research councils, particularly the Agricultural Research Council. The cost has not yet been settled, but the total so far committed is about three-quarters of a million pounds. Development of the system is being shared by the university and the manufacturers. Whether or not multi-access systems will be established at the two other centres has not yet been decided.

The University of Newcastle unon Tyne has already taken delivery of an American IBM 360/67 multi-access computing system which was installed in October and is currently undergoing tests. When operational, use of the machine will be shared by Newcastle and Durham Universities. $£ 575,000$ of the total cost of the computer was provided by a grant from the Computer Board. Communication terminals will be available in various departments of both universities and satellite computers can be attached to the central computer.

Research workers in two universities are developing their own multi-access facilities by building on to existing computers already at their disposal. Thus a smaller computer providing these facilities has been developed at Edinburgh University under Professor D. Michie for application to medical research work. This is based on the Elliott 41/20 model which was delivered in early 1966. The software has been produced in the university, but the cost of salaries and expenses was covered partly by the MRC, partly by the SRC and partly by the university itself. There are twenty consoles connected to the system, any eight of which can be used simultaneously. In addition there are two remote consoles which are attached by telephone: one is at the National Institute for Medical Research at Mill Hill and the other is at the Department of Social Medicine at Edinburgh. The system involving the twenty consoles has been operational since this summer, but the two remote consoles will not become operational until the end of the month.

Serious work on multi-access systems at Cambridge began at the end of 1964 with the design of a multiplexor to attach to the Titan computer. Development of the hardware was a joint exercise between the university and International Computers and Tabulators, Ltd. The cost of the consoles and multiplexor was met by the SRC while the disc store, which represented the major item of expenditure, was ultimately paid for by the Computer Board. By November this year the multi-access computing service was running at more than a hundred hours a week. At present there are about twenty-five consoles and between sixty and seventy regular users: most of the consoles are in the mathematical laboratory, but there are others in the engineering laboratory, the chemical engineering and the medical psychology laboratories. Workers at Cambridge maintain that the multi-access system has greatly increased the productivity of its users, and has materially diminished the demand for specially rapid service through the ordinary computing system.

Indeed, multiple access computing systems are very much a subject of objective research and exploration in leading British universities concerned with computer science. Applications for the time sharing systems are being considered by the Computer Board, which has in mind the linking up of computer systems in various universities, particularly in the south-west-to provide a complex computer network.

Despite the advantages of a multi-access system which gives a large number of users immediate access to the large computing system and which allows intimate contact between the worker and the tool as well as providing-in principle-quick and easy programme development, several problems have to be overcome. For example, considerable difficulties have arisen at Newcastle in connexion with the software and the system is far from satisfactory. Similar difficulties have been encountered in the USA with the same model. Evidently, the most economic arrangement has yet to be worked out

\section{Environmental Research}

The Natural Environment Research Council enters its second year in a better state of organization than in its first. The report of the council for the year ending March 31, 1967 (HMSO, 11s.), describes what has been happening. Broadly, the council seems to have been digging itself in as a permanent part of the Civil Service, by setting up a headquarters (from which it has since moved), establishing specialist committees, and defining the details of recruitment and employment of staff. Scientifically, the council is making an attempt to originate policies of its own, and organize 